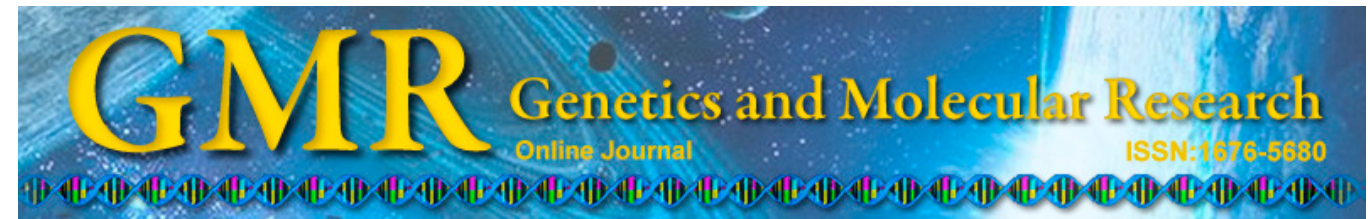

\title{
Variation and genetic structure of Tunisian Festuca arundinacea populations based on inter-simple sequence repeat pattern
}

\author{
N. Chtourou-Ghorbel ${ }^{1}$, H. Elazreg ${ }^{1}$, S. Ghariani ${ }^{1}$, N. Ben Mheni ${ }^{1}$, \\ M. Sekmani', M. Chakroun ${ }^{2}$ and N. Trifi-Farah ${ }^{1}$ \\ ${ }^{1}$ Laboratoire de Génétique Moléculaire, Immunologie et Biotechnologie, \\ Faculté des Sciences de Tunis, University Tunir El Manar, \\ Campus Universitaire, E1 Manar Tunis, Tunisie \\ ${ }^{2}$ Laboratoire des Productions Animales et Fourragères, \\ Institut National de la Recherche Agronomique de Tunisie, Ariana, Tunisie \\ Corresponding author: N. Trifi-Farah \\ E-mail: neilatrifi@gmail.com
}

Genet. Mol. Res. 14 (2): 3071-3081 (2015)

Received May 15, 2014

Accepted August 1, 2014

Published April 10, 2015

DOI http://dx.doi.org/10.4238/2015.April.10.17

\begin{abstract}
Tunisian tall fescue (Festuca arundinacea Schreb.) is an important grass for forages or soil conservation, particularly in marginal sites. Inter-simple sequence repeats were used to estimate genetic diversity within and among 8 natural populations and 1 cultivar from Northern Tunisia. A total of 181 polymorphic inter-simple sequence repeat markers were generated using 7 primers. Shannon's index and analysis of molecular variance evidenced a high molecular polymorphism at intra-specific levels for wild and cultivated accessions, showing that Tunisian tall fescue germplasm constitutes an important pool of diversity. Within-population variation accounted for $39.42 \%$ of the total variation, but no regional differentiation was discernible to designate close relationships between regions. Most of the variation $\left(G_{\mathrm{ST}}\right.$ $=67 \%$ ) occurred between populations, rather than within populations. The $\phi_{\mathrm{ST}}(0.60)$ revealed high population structuring. Additionally, the
\end{abstract}


population structure was independent of the geographic origin and was not affected by environmental factors. The unweighted pair group method with arithmetic mean tree based on genetic similarity and principal coordinate analysis based on coefficient similarity illustrated that continental populations from the proximate localities of Beja and Jendouba were genetically closely related, while the wild Skalba population from the littoral Tunisian locality was the most diverse from the others. Moreover, great molecular similarity of the spontaneous population Sedjnane originated from the mountain areas was revealed with the local cultivar Mornag. The observed genetic diversity can be used to implement conservation strategies and breeding programs for improving forage crops in Tunisia.

Key words: Analysis of molecular variance; Genetic structure; Festuca arundinacea Schreb.; Inter-simple sequence repeat markers; Shannon's index; Spontaneous and cultivated populations

\section{INTRODUCTION}

The Festuca sp genus contains approximately 500 species, some of which are commonly used as forage and turf grasses (Majidi et al., 2006; Inda et al., 2008). They belong to the grass family Poaceae, subfamily Pooideae, and tribe Poeae (Wheeler et al. 2002). Tall fescue (Festuca arundinacea Schreb.) is the most important perennial forage and turf grass species of this genus and is widely grown throughout temperate regions worldwide (Sleper, 1985; Saha et al., 2005). It is a hexaploid $(2 \mathrm{~N}=6 \mathrm{X}=42)$ with a genome size of 5.27-5.83 $\mathrm{x}$ $10^{6} \mathrm{~kb}$ (Seal, 1983). Tall fescue is also an open-pollinated species with a high level of selfincompatibility (Xu et al., 1991). This species is characterized by the persistence and tolerance to low levels of available nutriments and to extreme abiotic stresses, such as cold winters and summer drought.

In Northern Tunisia, this species is an important cool season bunch grass, widely used in pasture, lawns, and hays (Elazreg et al., 2011). However, it was at risk for severe genetic erosion because of overgrazing and irregularities in rainfall (Elazreg et al., 2011). Tunisian genetic resources are mainly constituted of natural populations; indeed, the introduction of some foreign cultivars in Tunisia have failed primarily because of their poor digestibility, low persistence, and unfortunate adaptability to Tunisian pedo-climatic conditions (ChtourouGhorbel et al., 2011). Only 3 local varieties (Mornag, Jebibina, and Grombalia) of $F$. arundinacea have been established (Chtourou-Ghorbel et al., 2012).

Studies of population genetic diversity using various molecular markers are very important for genetic resource characterization, protection, development-breeding programs, and sustainable utilization of these important agronomic resources (Sharma et al., 1996; Ghorbel et al., 2014; Marghali et al., 2014). Inter-simple sequence repeat (ISSR) polymorphism markers have been developed to investigate the genetic diversity of natural populations (Zietekiewicz et al., 1994). ISSR fingerprinting has revealed the hypervariable nature of the markers and its potential power for population studies (Ghariani et al., 2003; Xia et al., 2007; Yao et al., 2008). ISSR analysis is a polymerase chain reaction (PCR)-based technique using primers composed of microsatellite sequences. In addition, ISSR markers show better reproducibility than random 
amplified polymorphic DNAs (RAPDs) (Fang and Roose, 1997; Ge and Sun, 1999) and are easier to detect than amplified fragment length polymorphisms (AFLPs) (Marghali et al., 2014).

Studies of genetic variation and phylogenetic relationships are essential for the efficient selection of superior plant material and conducting introgression-breeding programs. In the present study, we developed an ISSR method as an alternative approach for generating powerful markers suitable for estimating genetic diversity levels within and among Tunisian tall fescue populations that are well-adapted to different bioclimatic stages compared with a local cultivar. Characterization of the local genetic resources is useful for establishing breeding programs.

\section{MATERIAL AND METHODS}

\section{Plant material}

The analysis was performed on 8 spontaneous populations and 1 cultivar collected from the north and the northwest of Tunisia from a range of habitats (Figure 1). The seeds of the studied populations were stored in a cold room of the Institut National de la Recherche Agronomique de Tunisie at $8^{\circ} \mathrm{C}$. Ten samples of each population were examined for genetic diversity. All considered populations and their pedo-climatic parameters are shown in Table 1.

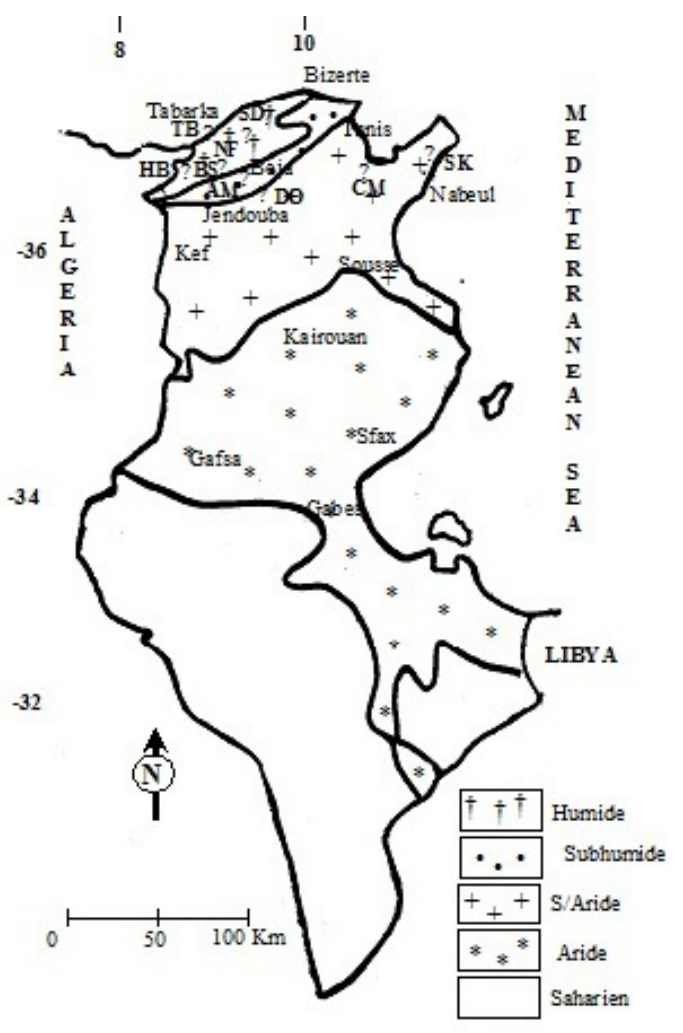

Figure 1. Geographic distribution of 9 populations of tall fescue sampled for ISSR analysis. The alphabetic codes of sample sites correspond to those in Table 1, and the same as in other figures and tables. 
Table 1. Description of pedo-climatic parameters at the collection sites of each tall fescue population.

\begin{tabular}{|c|c|c|c|c|c|c|c|c|c|c|c|}
\hline $\begin{array}{l}\text { Population } \\
\text { code }\end{array}$ & $\begin{array}{l}\text { Population } \\
\text { site }\end{array}$ & Locality & $\begin{array}{l}\text { Latitude } \\
\left({ }^{\circ} \mathrm{N}\right)\end{array}$ & $\begin{array}{c}\text { Longitude } \\
\left({ }^{\circ} \mathrm{E}\right)\end{array}$ & $\begin{array}{l}\text { Altitude } \\
(\mathrm{m})\end{array}$ & $\begin{array}{c}\text { Rainfall } \\
(\mathrm{mm})\end{array}$ & $\underset{\left({ }^{\circ} \mathrm{C}\right)}{\operatorname{Max} \mathrm{T}}$ & $\begin{array}{l}\text { Min T. } \\
\left({ }^{\circ} \mathrm{C}\right)\end{array}$ & Soil pH & $\begin{array}{l}\text { Soil } \\
\text { texture }\end{array}$ & $\begin{array}{l}\text { Anthropogenic } \\
\text { disturbances }\end{array}$ \\
\hline $\mathrm{AM}$ & Ain Melliti & Béja & $36^{\circ} 29^{\prime}$ & $9^{\circ} 9^{\prime}$ & 580 & 575 & 33.4 & 4.9 & 9.0 & clay & grazed \\
\hline DO & Dogga & Béja & $36^{\circ} 25^{\prime}$ & $9^{\circ} 12^{\prime}$ & 510 & 525 & 35.2 & 5.1 & 8.75 & clay & grazed \\
\hline NF & Nefza & Béja & $36^{\circ} 59^{\prime}$ & $9^{\circ} 4^{\prime}$ & 30 & 700 & 32.5 & 7.7 & 9.25 & clay & grazed \\
\hline BS & Bou Salem & Jendouba & $36^{\circ} 31^{\prime}$ & $8^{\circ} 57^{\prime}$ & 150 & 425 & 35.6 & 5.2 & 9.5 & clay & grazed \\
\hline TB & Tabarka & Jendouba & $36^{\circ} 56^{\prime}$ & $8^{\circ} 47^{\prime}$ & 12 & 1029 & 30.2 & 8.0 & 6.5 & loam & settlement \\
\hline HB & $\begin{array}{l}\text { Hammam } \\
\text { Bourguiba }\end{array}$ & Jendouba & $36^{\circ} 44^{\prime}$ & $8^{\circ} 39^{\prime}$ & 560 & 1200 & 31.3 & 3.9 & 6.25 & clay & grazed \\
\hline SD & Sedjnane & Bizerte & $37^{\circ} 03^{\prime}$ & $9^{\circ} 12^{\prime}$ & 116 & 650 & 32.5 & 7.7 & 6.75 & clay & grazed \\
\hline SK & Skalba & Nabeul & $36^{\circ} 49^{\prime}$ & $10^{\circ} 58^{\prime}$ & 18 & 425 & 29.5 & 8.6 & 8.6 & clay & grazed \\
\hline $\mathrm{CM}$ & Mornag & Ben Arous & $36^{\circ} 50^{\prime}$ & $10^{\circ} 11^{\prime}$ & 123 & 425 & 33.1 & 5.7 & 9.25 & clay & cultivated \\
\hline
\end{tabular}

\section{DNA extraction}

Total DNA was isolated from leaf tissues of each individual plant according to the method described by Dellaporta et al. (1983). Purified DNA was quantified both by a spectrophotometer and by ethidium bromide coloration after electrophoresis.

\section{ISSR amplification}

Seven oligonucleotides complementary to simple sequence repeats (SSRs) were tested among 9 populations. The primer sequences and their properties are summarized in Table 2.

For PCR amplification, a $25-\mu \mathrm{L}$ reaction mixture was used and contained 20-30 ng total cellular DNA, $60 \mathrm{pg}$ primers, $100 \mu \mathrm{M}$ of each dNTPs (DNA polymerization mix; Pharmacia, St. Quentin en Yveline, France), $2.5 \mu \mathrm{L}$ Taq DNA polymerase buffer (10X), and 1.5 U Taq DNA polymerase (Q-Biogène, Irvine, CA, USA).

PCR amplifications were carried out in a Crocodile III thermocycler (Q-Biogène) using a DNA-melting step that was 5 min at $94^{\circ} \mathrm{C}$, followed by 35 cycles, each including $30 \mathrm{~s}$ at $94^{\circ} \mathrm{C}$ for DNA melting, $90 \mathrm{~s}$ of each primer appropriate melting temperature $\left({ }^{\circ} \mathrm{C}\right)$ for annealing, and $90 \mathrm{~s}$ at $72^{\circ} \mathrm{C}$ for elongation. A final extension of $72^{\circ} \mathrm{C}$ for $5 \mathrm{~min}$ was also run.

Amplification products were separated by electrophoresis on a 1.5\% agarose gel in 0.5X Tris borate EDTA buffer, $\mathrm{pH} 8.3$, stained with ethidium bromide and visualized under UV light as described by Sambrook et al. (1989). The size of amplified fragments was estimated by comparison with 1-kb ladder loaded simultaneously with the amplified DNAs.

\section{Diversity analysis}

Amplified products were compiled into a binary data matrix based on the presence (1) or absence (0) of each selected band.

Shannon's index for the revealed ISSR loci was calculated for each population (Lewontin, 1972; Bussell, 1999) as $H_{\mathrm{j}}=-\sum p_{i} \log _{2} p_{i}$, where $p_{i}$ is the frequency of the ISSR marker $i$ in a population. The average diversity among all populations was calculated for each locus as:

$H_{\text {pop }}^{\prime}=1 / \mathrm{n} \sum H_{\mathrm{j}}^{\prime}$, where $n$ is the number of populations. Species diversity was calculated for each locus as: $H_{\mathrm{sp}}=-\sum p_{s} \log _{2} p_{s}$, where $p_{s}$ is the frequency of the ISSR marker in the entire sample (90 individuals in this study). Thus, for each locus, diversity within populations is $H_{\mathrm{pop}}^{\prime} / H_{\mathrm{sp}}^{\prime}$ and the component among populations is $G_{\mathrm{ST}}=\left(H_{\mathrm{sp}}^{\prime}-H_{\mathrm{pop}}^{\prime}\right) / H_{\mathrm{sp}}^{\prime}$. 
In addition, an analysis of molecular variance (AMOVA) procedure (Excoffier et al., 1992) was used to describe the genetic structure and variability among populations using ARLEQUIN Version 3.1 (Schneider et al., 2000). Variance components were tested statistically by nonparametric randomization tests using 10,100 random permutations. Corresponding estimates of gene flow $\left(N_{\mathrm{m}}\right)$, i.e., the average per generation number of migrants exchanged among populations, was calculated using the formula: $N_{\mathrm{m}}=0.5\left(1-G_{\mathrm{ST}}\right) / G_{\mathrm{ST}}(\mathrm{McDermott}$ and McDonald, 1993) by using POPGENE Version 1.32 (Yeh et al., 1999).

The binary data matrix was analyzed using the Numerical Taxonomy and Multivariate Analysis System (NTSYS-pc) (Rohlf, 2000). Genetic similarity was calculated according to the Dice coefficient (qualitative data module) (Dice, 1945), which corresponds to Nei and Li's similarity coefficient (Nei and Li, 1979). Unweighted pair group method with arithmetic mean (UPGMA) dendrogram using the Sequential Agglomerative Hierarchical Nested Cluster Analysis module of the NTSYS-pc software was applied to identify all trees that could result from different choices of tied similarity or dissimilarity values. The Mantel test (Mantel, 1967) was performed statistically using the XLSTAT software version 2010 (Addinosoft SARL, Paris, France) to compare genetic similarities and geographical distances among populations.

Principal coordinate analysis was conducted using the DCENTER and EIGEN programs as described by Gower (1996) in the NTSYS-pc software package version 2.1 (Rohlf, 2000). This multivariate approach was conducted in complement of the cluster analysis to define major groups (Hauser and Crovello, 1982).

\section{RESULTS}

Seven oligonucleotides complementary to SSRs were used among 8 spontaneous populations and 1 cultivar of the $F$. arundinacea. A total of 181 amplification products were generated, ranging in size from 220-3500 bp. The number of bands varied from 23 for the primer $(\mathrm{AG})_{10} \mathrm{C}$ to 29 for $(\mathrm{AG})_{10} \mathrm{G}$ and $(\mathrm{TC})_{10} \mathrm{~A}$, with an average of 25.86 bands per primer (Table 2). All ISSR bands generated by the different primers in each population were polymorphic. Depending on the population studied, variations were observed in the number (from 77 to 106) and the rates of polymorphic bands (ranged from 57.14 to $83.96 \%$ ) (Table 3). The cultivar Mornag (CM) appeared to be the least polymorphic in contrast to the spontaneous population Hammam Bourguiba that is the most diversified population. These results suggest that the ISSR procedure is a viable approach for examining tall fescue's genetic diversity.

Table 2. Summary of amplified DNA bands generated by seven primers used.

\begin{tabular}{|c|c|c|c|c|}
\hline \multirow[t]{2}{*}{ Primer sequence } & \multicolumn{2}{|c|}{$\operatorname{Tm}\left({ }^{\circ} \mathrm{C}\right)$} & \multicolumn{2}{|c|}{ Amplified DNA bands } \\
\hline & Theoretical & Optimal & Total & Polymorphic (\%) \\
\hline$(\mathrm{AG})_{10} \mathrm{C}$ & 64 & 60 & 23 & 100 \\
\hline$(\mathrm{AG})_{10} \mathrm{G}$ & 64 & 60 & 29 & 100 \\
\hline$(\mathrm{AG})_{10} \mathrm{~T}$ & 62 & 57 & 24 & 100 \\
\hline (CT) ${ }_{10}^{10} \mathrm{~T}$ & 62 & 57 & 27 & 100 \\
\hline (CT) ${ }_{10} \mathrm{~A}$ & 62 & 57 & 24 & 100 \\
\hline (TC) $\mathrm{A}$ & 62 & 57 & 29 & 100 \\
\hline (ACTG) & 48 & 45 & 25 & 100 \\
\hline Total & & & 181 & 100 \\
\hline
\end{tabular}


Shannon's index was used to quantify and partition ISSR diversity in 9 populations of tall fescue. Primers varied in their power to detect variation within and among populations. $H^{\prime}$, $H_{\text {pop }}^{\prime}$, and $H_{\text {sp }}^{\prime}$ were averaged over all loci using the 90 plant samples. As reported in Table 3, the wild population Ain Melliti (AM) showed the highest value of $H^{\prime}$ (10.062), while the CM exhibited the lowest value $\left(H_{\mathrm{j}}^{\prime}=4.725\right)$. Analysis of diversity with Shannon's index (Table 4) revealed that most ISSR variation $\left(G_{\mathrm{ST}}=67 \%\right)$ occurred among, rather than within, populations of tall fescue.

\begin{tabular}{|c|c|c|c|c|}
\hline \multirow{2}{*}{ Populations } & \multicolumn{3}{|c|}{ ISSR amplified bands } & \multirow[t]{2}{*}{$H_{\mathrm{j}}^{\prime}$} \\
\hline & Total & Polymorphic & РPB (\%) & \\
\hline SK & 81 & 68 & 83.95 & 8.666 \\
\hline AM & 104 & 77 & 74.04 & 10.062 \\
\hline BS & 89 & 69 & 77.53 & 8.508 \\
\hline $\mathrm{HB}$ & 106 & 89 & 83.96 & 9.569 \\
\hline $\mathrm{NF}$ & 102 & 76 & 74.51 & 9.003 \\
\hline DO & 84 & 68 & 80.95 & 7.601 \\
\hline $\mathrm{CM}$ & 77 & 44 & 57.14 & 4.725 \\
\hline SD & 84 & 63 & 75.00 & 7.230 \\
\hline TB & 84 & 58 & 69.05 & 7.241 \\
\hline
\end{tabular}

Table 4. Partitioning of genetic diversity generated by 7 ISSR primers into within- and between-population components for nine populations of tall fescue.

\begin{tabular}{lcccc}
\hline Primer & $H_{\text {pop }}^{\prime}$ & $H_{\text {sp }}^{\prime}$ & $H_{\text {pop }}^{\prime} / H_{\text {sp }}^{\prime}$ & $G_{\text {ST }}$ \\
\hline $5^{\prime}(\mathrm{AG})_{10} \mathrm{C} \mathrm{3}^{\prime}$ & 1.08 & 2.65 & 0.41 & 0.59 \\
$5^{\prime}(\mathrm{AG})_{10} \mathrm{G} \mathrm{3}^{\prime}$ & 1.08 & 3.95 & 0.27 & 0.73 \\
$5^{\prime}(\mathrm{AG})_{10} \mathrm{~T}^{\prime}$ & 0.88 & 3.24 & 0.27 & 0.73 \\
$5^{\prime}(\mathrm{CT})_{10} \mathrm{~T}^{\prime}$ & 1.16 & 3.72 & 0.31 & 0.69 \\
$5^{\prime}(\mathrm{CT})_{10} \mathrm{~A} 3^{\prime}$ & 1.33 & 3.59 & 0.37 & 0.63 \\
$5^{\prime}(\mathrm{TC})_{10} \mathrm{~A} 3^{\prime}$ & 1.51 & 3.93 & 0.38 & 0.62 \\
$5^{\prime}(\mathrm{ACTG})_{4} 3^{\prime}$ & 1.02 & 3.28 & 0.31 & 0.69 \\
Total & 8.06 & 24.36 & 0.33 & 0.67 \\
\hline
\end{tabular}

Partitioning of molecular variance was analyzed among the geographical origin corresponding to 5 regions (Béja, Jendouba, Nabeul, Bizerte, and Ben Arous) and among populations within regions (Table 5). There was a highly significant contribution of the variance between populations within regions and within populations to the total variance $(\mathrm{P}<0.001)$. Among regions, AMOVA showed no significant genetic variation, indicating close relationships between the 5 localities. Of the total genetic diversity, only $0.67 \%$ was attributable to differences among regions, $59.91 \%$ to population differences within regions, and $39.42 \%$ to differences within populations. This indicates that the genetic variation mainly occurred among populations rather than between regions. These results corroborate the finding by Shannon's index either about the within-or-between population variance. The $\phi_{\mathrm{ST}}(0.60)$ showed high population structuring. The significant values of the $\Phi_{\mathrm{ST}}$ matrix pair-by-pair between populations confirmed the high differentiation of Tunisian tall fescue (Table 6). Furthermore, the level of gene flow $\left(N_{\mathrm{m}}\right)$ was measured to be 0.3818 individual per generation between populations, suggesting that gene exchange between populations was low. 
Table 5. Analysis of molecular variance (AMOVA) for 181 ISSR markers in populations studied.

\begin{tabular}{|c|c|c|c|c|c|}
\hline Source of variation & d.f. & SSD & Variance components & $\%$ of the total variance & $P$ value \\
\hline Among regions & 4 & 929.644 & 0.24067 & 0.67 & 0.373 \\
\hline Among populations within regions & 4 & 913.600 & 21.43012 & 59.91 & 0.000 \\
\hline Within populations & 81 & 1142.000 & 14.09877 & 39.42 & 0.000 \\
\hline Total & 89 & 2985.244 & 35.76956 & & \\
\hline
\end{tabular}

Levels of significance were based on 10,100 random permutations. df: degrees of freedom; SSD: sum of squared deviations; P value: probability of obtaining a more extreme component estimate by chance alone. The total data set contain individuals from five regions (Béja, Jendouba, Bizerte, Nabeul, and Ben Arous).

\begin{tabular}{|c|c|c|c|c|c|c|c|c|c|}
\hline & SK & $\mathrm{CM}$ & $\mathrm{AM}$ & DO & $\mathrm{NF}$ & BS & $\mathrm{HB}$ & TB & SD \\
\hline SK & 0.00000 & & & & & & & & \\
\hline $\mathrm{CM}$ & 0.68357 & 0.00000 & & & & & & & \\
\hline $\mathrm{AM}$ & 0.52473 & 0.65920 & & & & & & & \\
\hline DO & 0.58346 & 0.67559 & 0.61923 & 0.00000 & & & & & \\
\hline $\mathrm{NF}$ & 0.59972 & 0.68804 & 0.53186 & 0.63388 & 0.00000 & & & & \\
\hline BS & 0.57487 & 0.68486 & 0.47355 & 0.62409 & 0.54909 & 0.00000 & & & \\
\hline HB & 0.58828 & 0.65863 & 0.43380 & 0.64304 & 0.47278 & 0.50050 & 0.00000 & & \\
\hline TB & 0.57096 & 0.69043 & 0.60437 & 0.56536 & 0.62683 & 0.59124 & 0.60274 & 0.00000 & \\
\hline SD & 0.60840 & 0.67709 & 0.61548 & 0.63831 & 0.63923 & 0.62894 & 0.59964 & 0.63772 & 0.00000 \\
\hline
\end{tabular}

Relationships among populations were estimated from the ISSR data using the UPGMA clustering method based on genetic similarity (Dice coefficient). The grouping analysis (UPGMA) tree (Figure 2) showed a clear structuring of all populations, exhibiting all individuals from the same population in 1 group.

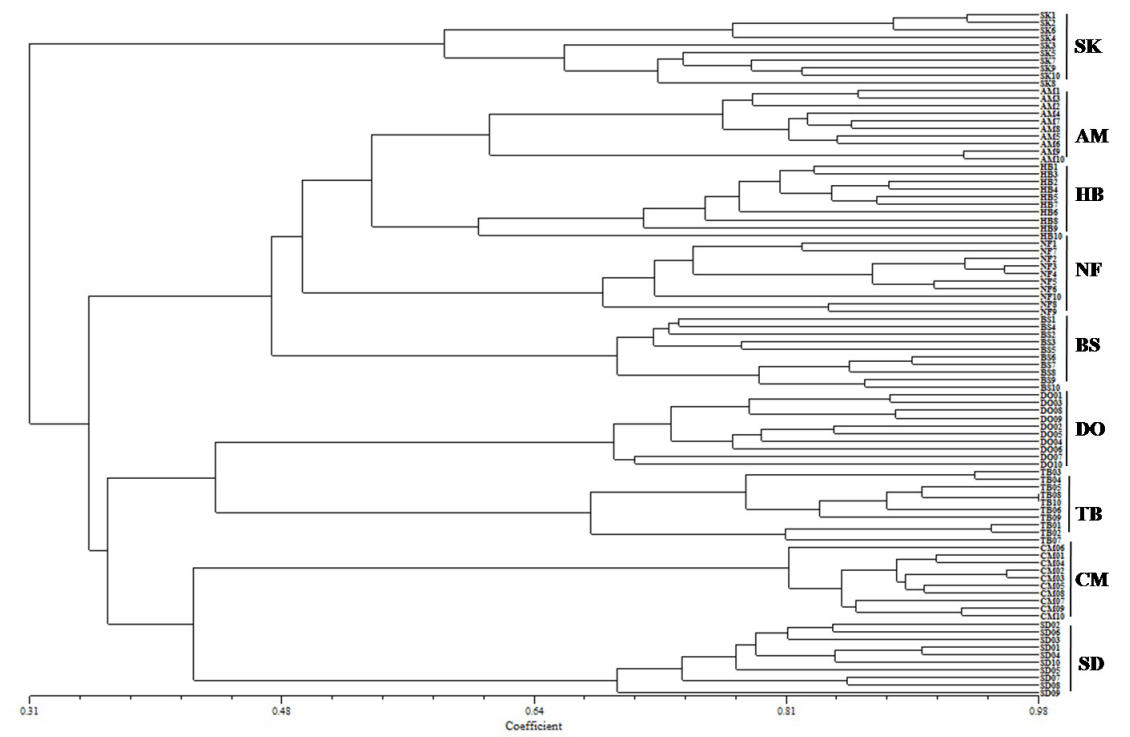

Figure 2. UPGMA dendrogram showing the relationship among the populations studied from Dice similarity coefficients based on 181 ISSR markers. 
The dendrogram at the level of 0.31 genetic similarities separated the samples into 2 main clusters. The first included the individuals belonging to the wild population of Skalba from the littoral Tunisian Cap Bon, whereas the second consisted of the remaining populations, which were subdivided in 2 subclusters. One corresponded to the populations of Nefza, Ain Melliti, Hammam Bourguiba, and Bou Salem, originating either from the continental and proximate localities of Béja or Jendouba. The second subcluster contained the cultivated population CM and the spontaneous populations SD, Tabarka, and Dogga (DO), corresponding to mountain areas. According to cluster analysis, the cultivated population CM and spontaneous population SD were closely related. Furthermore, the observed clustering was independent of the geographical origin of populations and bioclimatic stages. Populations from 5 geographical regions were to a large intermingled in the UPGMA. The result of the Mantel test with 10,000 permutations revealed a negative correlation between matrices of geographic distance and of genetic distance based on ISSR data $(r=-0.280, \mathrm{P}=0.046)$.

The principal coordinate analysis based on Jaccard's (1908) similarity coefficient was examined. Our principal coordinate plot showed that most individuals from a given population were generally clustered together, making them more genetically similar than individuals from different populations (Figure 3). The first 3 principle axis accounted for 10.36, 8.38, and $7.12 \%$ of the total genetic variation, respectively.



Figure 3. Plot of first 2 principal coordinate axes for 9 populations based on Jaccard's similarity coefficients using the ISSR data (see Table 1 for population codes). 
The PC1 vs PC2 plot (Figure 3) revealed 3 main groups. The first included Hammam Bourguiba, Bou Salem, Ain Melliti, and Nefza accessions. The second group is composed of Skalba, Tabarka, and Dogga populations, while the CM and the spontaneous population of SD represented the third group. In general, the principal coordinate analysis supported the conclusions of cluster analysis.

\section{DISCUSSION}

Using ISSR primers, our results revealed considerable genetic diversity within populations of Tunisian tall fescue. In fact, 181 bands were polymorphic in the 9 populations studied and the percentage of polymorphic bands in each population ranged from 57.14 to $83.96 \%$. Similar results were reported by Hou et al. (2005) in the study of the genetic diversity of 46 barley accessions by RAPD and ISSR markers. The results indicated that the percentage of ISSR polymorphic bands (98.13\%) was higher than that found using RAPD (77.06\%). Using ISSR primers, Xia et al. (2005) found that $80 \%$ of the bands were polymorphic in 10 populations of Rhodiola alsia, ranging from 63.37 to $88.57 \%$ in each population. The results of these studies indicate that ISSR technology is a powerful and an efficient approach, which can supply sufficient information in diversity analysis either at the intra- or inter-populations level.

The observed heterogeneity of tall fescue may be the result of cross-pollination considering the allogamous-mating system of this species. Life form and breeding systems may significantly influence genetic variation and its partitioning (Hamrick and Godt, 1996). Selfing species are frequently characterized by a high degree of population genetic differentiation and relative uniformity within populations, while outcrossing species tend to be more varied within, with less genetic differentiation, between populations. In addition, the $G_{\mathrm{ST}}$ estimation using Shannon's index ranged from 15 to $38 \%$ for 30 outbreeding species (Bussell, 1999). However, exceptions can occur. In fact, Gustafsson and Gustafsson (1994) found $G_{\mathrm{ST}}=81 \%$ for outcrossing species Vicia pisiformis. Chalmers et al. (1992), studying the obligatory outbreeding species Gliricidia sepium, found that $60 \%$ of the diversity occurred between populations $\left(G_{\mathrm{ST}}=59.9 \%\right)$. In our study, the $G_{\mathrm{ST}}$ value for $F$. arundinacea $(67 \%)$ was close to the last value. The pronounced genetic differentiation among populations has been attributed to low inter-population gene flow $\left(N_{\mathrm{m}}=0.3818\right)$. These results appear to be due to the collection of populations from the large range of a widespread species and indicated large-scale divergence, rather than being because of reproductive or other life-history traits. Studying 52 populations of Silene dioica using allozyme analysis, Giles and Goudet (1997) found that the turnover of local populations along with environmental heterogeneity and spatial restriction increased genetic variation among populations. This also suggested that the sampling strategy is an important factor in genetic diversity studies, and the samples should represent all types of habitats and distribution of the species to the greatest extent possible.

AMOVA partition indicated that the genetic variation mainly occurred among populations rather than between regions. Of the total genetic diversity, 59.91\% was attributable to differences among populations within regions, $39.42 \%$ to differences within populations, and only $0.67 \%$ to differences between regions. As reported in outcrossing and selfing species, the level of partitioning of molecular variance varies depending on the range of material under study and on the breeding systems of the species involved. In Medicago sativa, an outcrossing species, Crochemore et al. (1996) found that variance within populations accounted for 50.6\% of the total variation. In Rhodiola chrysanthemifolia, Xia et al. (2007) used AMOVA and found that 
genetic variation among populations was $77.3 \%$, within populations was $22.7 \%$, and showed no regional differentiation. Huff et al. (1993) reported large regional differences for 48 individuals of Buffalo grass (Buchloë dactyloides), but much smaller differences between populations within regions. In our study, $59.91 \%$ of total genetic variation was observed among populations of tall fescue, indicating the need to conserve more populations to maintain this species.

Examination of the UPGMA dendrogram revealed clustering populations independently of their geographical origin and climatic characteristics. Moreover, the ISSR phylogram revealed that the continental populations from Béja and Jendouba were genetically closely related, while the littoral population of Skalba from the Nabeul region was the most diverse compared to the other populations studied. Notably, CM was clustered with the spontaneous accession of SD from the mountain areas. The high genetic similarity between these spontaneous and cultivated forms can be effectively utilized in valorization programs of local germplasm. Moreover, the analyzed pedo-climatic factors, particularly altitude, rainfall, and soil $\mathrm{pH}$, were not significant for grouping of the analyzed populations. Overall, our data agree with a previous study based on morpho-agronomical traits and AFLP markers (ChtourouGhorbel et al., 2011; Elazreg et al., 2011). The independent genotypic structure of Tunisian tall fescue populations from the environment factors supports high-adaptive power aptitude species to large-scale ecological variations.

In conclusion, this study supports that ISSR markers are effective for assessing molecular polymorphisms and phylogenetic relationships in Tunisian tall fescue. The potential use of ISSR markers for studying the population structure of $F$. arundinacea was demonstrated. These markers can also be used in the study of other Festuca species. Furthermore, our data revealed the important genetic variability among and within populations of $F$. arundinacea as an alternative pool of diversity that can be used in improvement programs.

\section{ACKNOWLEDGMENTS}

Research partially supported by grants from the Tunisian Ministère de l'Enseignement Supérieur, de la Recherche Scientifique: project \#LR B02.

\section{REFERENCES}

Bussell JD (1999). The distribution of random amplified polymorphic DNA (RAPD) diversity among populations of Isotoma petraea (Lobeliaceae). Mol. Ecol. 8: 775-789.

Chalmers KJ, Waugh R, Sprent JI, Simons AJ, et al. (1992). Detection of genetic variation between and within populations of Gliricidia sepium and G. muculata. Heredity 69: 465-447.

Chtourou-Ghorbel N, Chakroun M, Elazreg H and Trifi-Farah N (2011). Agronomic evaluation and Genetic variation of Tunisian tall fescue (Festuca arundinacea Schreb.). Int. J. Agron. 2011: 1-6.

Chtourou-Ghorbel N, Elazreg H, Ghariani S, Chakroun M, et al. (2012). Genetic diversity among wild accessions and cultivars of Tunisian tall fescue based on morpho-agronomical traits and ISSR markers. J. Food Agric. Environ. 10: 263-268.

Crochemore ML, Huyghe C, Kerlan MC, Durand F, et al. (1996). Partitioning and distribution of RAPD variation in a set of populations of the Medicago sativa complex. Agronomy 16: 421-432.

Dellaporta SL, Wood J and Hicks JB (1983). A plant DNA minipreparation: version II. Plant. Mol. Biol. Rep. 1: 19-21.

Dice LR (1945). Measures of the amount of ecologic association between species. Ecology 26: 297-302.

Elazreg H, Chtourou-Ghorbel N, Ghariani S, Chakroun M, et al. (2011). Studying genetic diversity of the Tunisian Lolium perenne and Festuca arundinacea with AFLP markers. J. Food Agric. Environ. 9: 409-415.

Excoffier L, Smouse PE and Quattro JM (1992). Analysis of molecular variance inferred from metric distances among haplotypes: application to human mitochondrial DNA restriction data. Genetics 131: 479-491.

Fang DQ and Roose ML (1997). Identification of closely related Citrus cultivars with inter-simple sequence repeat 
markers. Theor. Appl. Genet. 95: 408-417.

Ge XJ and Sun M (1999). Reproductive biology and genetic diversity of a cryptoviviparous mangrove Aegiceras corniculatum (Myrsinaceae) using allozyme and inter-simple sequence repeat (ISSR) analysis. Mol. Ecol. 8: 2061-2069.

Ghariani S, Trifi-Farah N, Chakroun M, Marghali S, et al. (2003). Genetic diversity in Tunisian perennial ryegrass revealed by ISSR markers. Genet. Res. Crop Evol. 5: 809-815.

Ghorbel M, Marghali S, Trifi-Farah N and Chtourou-Ghorbel N (2014). Phylogeny of Mediterranean Lathyrus species using Inter Simple Sequence Repeats markers. Acta Bot. Gal. 161: 91-98.

Giles BG and Goudet J (1997). Genetic differentiation in Silene dioica metapopulations: estimation of spatiotemporal effects in a successional plant species. Am. Nat. 149: 507-526.

Gower JC (1996). Some properties of latent root and vector methods used in multivariate analysis. Biometrika 53: 325-338.

Gustafsson L and Gustafsson P (1994). Low genetic variation in Swedish populations of the rare species Vicia pisiformis (Fabaceae) revealed with RFLP (rDNA) and RAPD. Plant System. Evol. 189: 133-148.

Hamrick JL and Godt MJW (1996). Effect of life history traits on genetic diversity in plant species. Philos. Trans. R. Soc. Lond. B. Biol. Sci. 351: 1291-1298.

Hauser LA and Crovello TJ (1982). Numerical analysis of genetic relationships in Thelypodieae (Brassicaceae). Syst. Bot. 7: 249-268.

Hou YC, Yan ZH, Wei YM and Zheng YL (2005). Genetic diversity in barley from west China based on RAPD and ISSR analysis. Barley Genet. New. 35: 9-22.

Huff DR, Peakall R and Smouse PE (1993). RAPD variation within and among natural populations of outcrossing buffalograss [Buchloë dactyloides (Nutt.) Engelm.]. Theor. Appl. Genet. 86: 927-934.

Inda LA, Segarra-Moragues JG, Müller J, Peterson PM, et al. (2008). Dated historical biogeography of the temperate Loliinae (Poaceae, Pooideae) grasses in the northern and southern hemispheres. Mol. Phyl. Evol. 46: 932-957.

Jaccard P (1908). Nouvelles recherches sur la distribution florale. Bull. Soc. Vaud. Sci. Nat. 44: 223-270.

Lewontin RC (1972). The apportionment of human diversity. Evol. Biol. 6: 381-398.

Majidi MM, Mirlohi AF and Sayed-Tabatabaei BE (2006). AFLP analysis of genetic variation in Iranian fescue accessions. Pakistan J. Biol. Sci. 9: 1869-1876.

Mantel N (1967). The detection of disease clustering and a generalized regression approach. Cancer Res. 27: 209-220.

Marghali S, Zitouna N, Gharbi M, Chennaoui-Kourda H, et al. (2014). Morphological and molecular characters: Congruence or conflict in the phylogeny of Sulla species? Aust. J. Crop Sci. 8: 148-158.

McDermott J and McDonald B (1993). Gene flow in plant pathosystems. Annu. Rev. Phytopathol. 31: 353-373.

Nei M and Li W (1979). Mathematical model for studying genetical variation in terms of restriction endonucleases. Proc. Nat. Acad. Sci. USA. 76: 5269-5273.

Rohlf FJ (2000). NTSYS-pc Numerical Taxonomy and Multivariate Analysis System, Version 2.1. Exeter Software, Setauket.

Saha MC, Mian R, Zwonitzer JC, Chkhovskiy K, et al. (2005). An SSR and AFLP based genetic linkage map of tall fescue (Festuca arundinacea Schreb.). Theor. Appl. Genet. 110: 323-336.

Sambrook J, Fritsch EF and Maniatis T (1989). Molecular cloning: a laboratory manual. Cold Spring Harbor Laboratory Press, Cold Spring Harbor.

Schneider S, Küffer JM, Rössli D and Excoffier L (2000). Arlequin, Version 3.1: a Software for Population Genetic Data Analysis. Genetics and Biometry Laboratory, University of Geneva, Geneva.

Seal AG (1983). DNA variation in Festuca. Heredity 50: 225-236.

Sharma SK, Knox MR and Ellis THN (1996). AFLP analysis of the diversity and phylogeny of Lens and its comparison with RAPD analysis. Theor. Appl. Genet. 93: 751-758.

Sleper DA (1985). Breeding tall fescue. Plant Breed. Rev. 3: 313-342.

Wheeler DJB, Jacobs SWL and Whalley RDB (2002). Grasses of New South Wales. University of New England Printery, Armidale.

Xia T, Chen SL, Chen SY and Ge X (2005). Genetic variation within and among populations of Rhodiola alsia (Crassulaceae), native to the Tibetan plateau as detected by ISSR markers. Biochem. Genet. 43: 87-101.

Xia T, Chen S, Chen S, Zhang D, et al. (2007). ISSR analysis of genetic diversity of the Qinghai-Tibet Plateau endemic Rhodiola chrysanthemifolia (Crassulaceae). Biochem. System. Ecol. 35: 209-214.

Xu W, Sleper DA and Hoisington GF (1991). A survey of restriction fragment length polymorphisms in tall fescue and its relatives. Genome 34: 686-692.

Yao H, Zhao Y, Chen DF, Chen JK, et al. (2008). ISSR primer screening and preliminary evaluation of genetic diversity in wild populations of Glycyrrhiza uralensis. Biol. Plant 52: 117-120.

Yeh F, Yang R and Boyle T (1999). POPGENE Version 1.32. Microsoft Window-based Freeware for Population Genetic Analysis. Molecular Biology and Biotechnology Center, University of Alberta, Edmonton.

Zietekiewicz E, Rafalski A and Labuda D (1994). Genome fingerprinting by simple sequence repeat (SSR)-anchored polymerase chain reaction amplification. Genomics 20: 176-183. 